\title{
A Computational Model of Pragma-dialectics as a Tool for its Analysis and Appraisal
}

\author{
AleJandro Secades \\ Department of Philosophy I \\ University of Granada, Campus de Cartuja \\ Granada, Spain \\ alexsecades@gmail.com
}

\begin{abstract}
The overall goal of this paper is to show that computational modelling of argumentation theories is a useful tool to deepen them. Specifically, it provides a basic computational formalization of part of Pragma-dialectics' model of a critical discussion, which serves as a basis for analyzing this influential theory of argumentation. Such analysis reveals some weaknesses and leaves some questions opened for Pragma-dialectics. Particularly, it shows that the model of a critical discussion is not independent of the model of reasoning/inference chosen, because, while it performs differently with different models of reasoning, it does not work well with some of them.
\end{abstract}

Résumé: L'objectif global de cette étude est de montrer que la modélisation informatique des théories de l'argumentation est un outil utile pour les approfondir. Plus précisément, il offre une formalisation de calcul de base d'une partie du modèle de la Pragma-dialectique d'une discussion critique, qui sert de base pour analyser cette théorie influente de l'argumentation. Cette analyse révèle certaines faiblesses et laisse quelques questions ouvertes pour la Pragma-dialectique. En particulier, elle montre que le modèle d'une discussion critique n'est pas indépendant du modèle de raisonnement / inférence choisi, parce que, d'une part, il opère différemment avec différents modèles de raisonnement et, d'autre part, il ne fonctionne pas bien avec certains d'entre eux.

Keywords: Argumentation theory, computational argumentation, defeasible logic, formal logic, Pragma-dialectics

\section{Why formalizing Pragma-dialectics?}

Pragma-dialectics is one of the most remarkable proposals within Argumentation Theory. It characterizes argumentation as a process for the resolution of a difference of opinion and proposes an ideal model, the critical discussion, which serves both to interpret and to evaluate actual arguments, based on their prox- 
imity to, or distance from, this ideal model ${ }^{1}$. Thus, the model plays both a descriptive role and a normative role.

The model of a critical discussion has been characterized and developed in an "informal" way, so as to allow some flexibility in its application to everyday argumentation, which is (mostly) conducted in natural, non-formal languages. This paper builds a computational and formal model of a critical discus$\operatorname{sion}^{2}$ taking as a basis its characterization in van Eemeren \& Grootendorst (2004). Such a model is meant to be more accurate than informal descriptions of the critical discussion, and therefore, it should make easier the task of finding the properties, strengths and weaknesses of Pragma-dialectics. This is the main purpose of this paper.

On the other hand, a computational model can help to evaluate whether the model of a critical discussion is of interest to the field of Computational Argumentation and, in general, whether or not it can help to produce good argumentative discourses, not just to analyze and evaluate them ${ }^{3}$.

In the next section I present the computational model of a critical discussion. In section 3, with the help of the computational model, I find and analyze a limitation of the rules of a critical discussion, while exploring possible solutions. Then, in section 4 I analyze the role of the model of reasoning (i.e., the inference rules allowed) in Pragma-dialectics, and in sections 5 and 6 I test the computational model of a critical discussion with different models of reasoning, and I analyze the results.

\footnotetext{
1 That is, in order to evaluate actual argumentative discourse, we have to reconstruct it as a critical discussion (which is an idealization of argumentative discourse). Once we build the critical discussion (that reflects actual argumentative discourse), we can evaluate it by checking whether or not discussants follow the rules constitutive of a critical discussion and whether or not a certain standpoint has been successfully defended.

2 Recently, Visser (2013) has provided a proposal of formalizing Pragmadialectics. However, the perspective and the technical tools employed are rather different (e.g., the formalization is based on dialogue games). Visser's proposal is in line with previous works by Krabbe (Visser, 2013, p. 4). Cf. (Bermejo-Luque \& Secades, 2013) for an analysis of Visser's work.

${ }^{3}$ In the presentation of their book, van Eemeren and Grootendorst say that their model of a critical discussion can serve "as a theoretical tool for analyzing, evaluating and producing argumentative discourse" (2004, p. i). However, it is proposed within the book as just a "theoretical model for examining argumentative discourses and texts" (p. 190). A computational model can help us to see how and whether the model of a critical discussion can be followed by actual discussant as a guide to produce good argumentative discourses: i.e., we can see whether the algorithm defined by the 15 rules can lead the contenders to a result in a finite time or whether it is too complex to be followed. In section 7, I go back to this issue.
}

(C) Alejandro Secades. Informal Logic, Vol. 35, No. 3 (2015), pp. 342-377. 


\section{A basic computational model of Pragma-dialectics' model of a critical discussion}

In this section I am going to build a computational model of a critical discussion. "Computational model" can be understood in many different ways, so, in first place, I have to clarify what I mean by it.

A model is always a model of something. In this case, I am going to model the description of a critical discussion, which is itself a model (an ideal model of the process of resolution of a difference of opinion). My model is computational in the sense that it is going to be built using computational techniques, taken from Software Engineering. Such a model is meant to accurately represent properties and behaviour of the critical discussion (the thing to be modelled) from a certain point of view and for a certain purpose. In this particular case, I am not interested in building software. Instead, I am going to focus on the relationship among the different procedures, states, events and dialectical moves that can occur during the process of resolution of a difference of opinion based in a critical discussion, in order to analyze some key aspects of Pragma-dialectics. As long as the computational model is good, its behaviour and properties will accurately reflect the behaviour and properties of a critical discussion ${ }^{4}$. To build this model, UML (Unified Modeling Language) diagrams will be used ${ }^{5}$.

So, let me begin with our model of a critical discussion. Pragma-dialectics distinguishes four types of differences of opinion. I will start with the basic one, namely, a single, nonmixed difference of opinion ${ }^{6}$. I will also consider other types of differences of opinion, but it is important to keep in mind that the rules of a critical discussion, as enunciated by Pragmadialectics, only deal with that basic type.

\footnotetext{
${ }^{4}$ Of course, that is right only for the point of view and purpose taken for the computational model. A computational model will not reflect everything about the thing to be modelled, but some aspects considered important.

${ }^{5} \mathrm{See}$ http://www.uml.org for a description and detailed specification of UML language. UML is de facto standard to model, analyze and design softwarebased systems, and is also widely used for modeling business and similar processes. It has many advantages over other diagraming techniques like flow-charts.

${ }^{6}$ A difference of opinion is single if it is about a single standpoint. It is nonmixed if the difference consists in one participant advancing a standpoint and the other, simply, questioning it (van Eemeren \& Grootendorst, 2004, pp. 60, 119-120). "Other sorts of difference of opinion consist of a combination of differences of opinion of the basic type" (p. 120).
}

(C) Alejandro Secades. Informal Logic, Vol. 35, No. 3 (2015), pp. 342-377. 
The general process of resolving a difference of opinion through a critical discussion has four successive stages (van Eemeren \& Grootendorst, 2004, pp. 59-62):

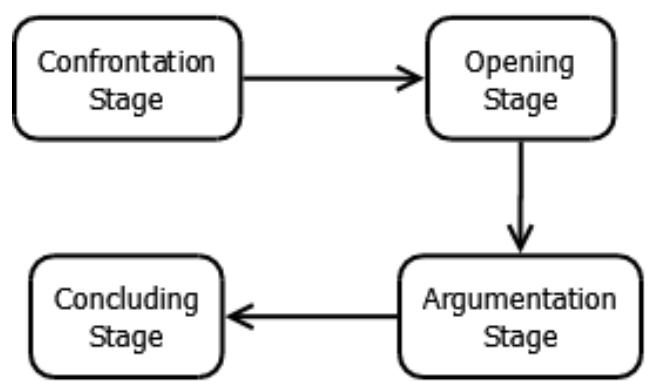

Figure 1: Stages in a critical discussion

According to Pragma-dialectics, each stage can be briefly defined as follows:

The confrontation stage in which the difference of opinion is developed, the opening stage in which the procedural and the other starting points are established, the argumentation stage in which the argumentation is put forward and subjected to critical reaction, and the concluding stage in which the outcome of the discussion is determined (van Eemeren \& Grootendorst, 2004, p. 134).

The core of the process of resolving a difference of opinion is placed in the Argumentation Stage. Thus, for our purpose of modeling differences of opinion, we can assume that, in the two previous stages, the contenders have decided to start a critical discussion on a standpoint (single, non-mixed difference of opinion) and that they have agreed the general rules and issues required by a critical discussion (including the list of propositions accepted by both contenders).

Given the rules for a critical discussion proposed by Pragma-dialectics, we can see a general overview of the Argumentation Stage in the following diagram ${ }^{7}$ :

\footnotetext{
${ }^{7}$ I use UML State Machine diagrams (also known as State Charts). Rounded rectangles are states of the argumentation process, black circles are the starting and ending points of the process and arrows are transitions between states, motivated by dialectical moves. Squares with text and a "fold" in a corner are comments to better understand the diagram. The texts of the arrows in the brackets indicate the events that cause the transition.
}

(C) Alejandro Secades. Informal Logic, Vol. 35, No. 3 (2015), pp. 342-377. 


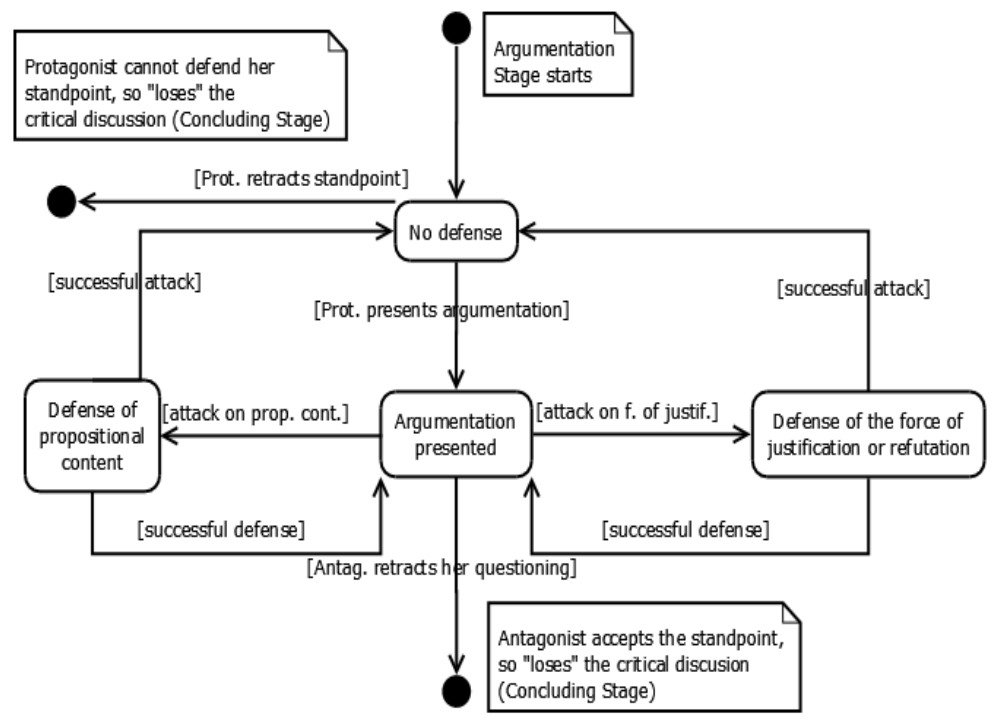

Figure 2: General overview of a critical discussion, Argumentation Stage

Let me comment briefly on this diagram ${ }^{8}$. When the Argumentation Stage starts, the protagonist (protagonist/antagonist roles are defined by rule 4) has a standpoint that she must defend (the burden of the proof is on her, as accredited by rules 2 and 3). To defend her standpoint, she has to raise an argument ${ }^{9}$ (rule 6).

Once the argumentation is presented, the antagonist has, in turn, two options: (a) she can accept the argumentation ${ }^{10}$ - thus, she will retract from her questioning the standpoint, and the protagonist will have "won" the critical discussion (Concluding

${ }^{8}$ Rules for a critical discussion are described in chapter 6 of van Eemeren and Grootendorst (2004). For simplicity sake, rather than filling the following paragraphs with references to that chapter, I shall indicate which of the 15 rules is behind each aspect of the commented diagram.

${ }^{9}$ In Pragma-dialectics, an argument is a complex act of argumentation, consisting of the reasons (speech acts) that support a standpoint. Conclusions are not taken to be part of arguments, although the relationship between an argument and its conclusion is a basic property of the argument (cf. van Eemeren \& Grootendorst, 1984, pp. 33-40). Contrastingly, the classical notion of "argument" usually refers to a set of premises and a conclusion.

${ }^{10}$ Indeed, the antagonist has to accept the argumentation if it has been successfully defended from her attacks (rule 9, see below). However, she can also accept it if she just cannot find a successful attack for that argumentation.

${ }^{11}$ A critical discussion has a goal: to resolve a difference of opinion. So, strictly speaking, there are no "winners" or "losers". When I say that the protagonist "wins" the critical discussion I simply say that she has defended her standpoint successfully, so that the antagonist has to accept it. It is the same for "losing" the critical discussion (she must retract her standpoint).

(C) Alejandro Secades. Informal Logic, Vol. 35, No. 3 (2015), pp. 342-377. 
Stage, rule 14), or (b) she can attack the argumentation (rule 10) either by attacking or questioning its propositional content (in other words, the correction of the premises), or by questioning its force of justification or refutation (rule 6).

If the antagonist attacks the argumentation, her attack can either succeeds or not (rule 9). If the attack, whatever its type, is successful, then the protagonist must retract the argumentation presented. In this case, contenders go back to the initial state (labelled "No defense"). In the initial state ("No defense"), the protagonist can retract her standpoint anytime, and she has to do it if the antagonist has attacked successfully the argumentation presented. This means that she "loses" the critical discussion (Concluding Stage, rule 14). In turn, if the attack is not successful, contenders go back to the "Argumentation presented" state. In this case, the antagonist would have to either make a different attack over the argumentation or accept it. In the latter case, she is accepting that the argumentation has been successfully defended, so she must retract from her questioning the standpoint (rule 14, see above).

Pragma-dialectics defines what is a proper defense for each type of attack - that is, attacks over the propositional content or over the force of justification or refutation of an argument. Each process is represented in the next two diagrams. They correspond to each "Defense of..." states in the above diagram. The following diagram represents the process when the propositional content of the argument is attacked ${ }^{12}$ (rule 7):

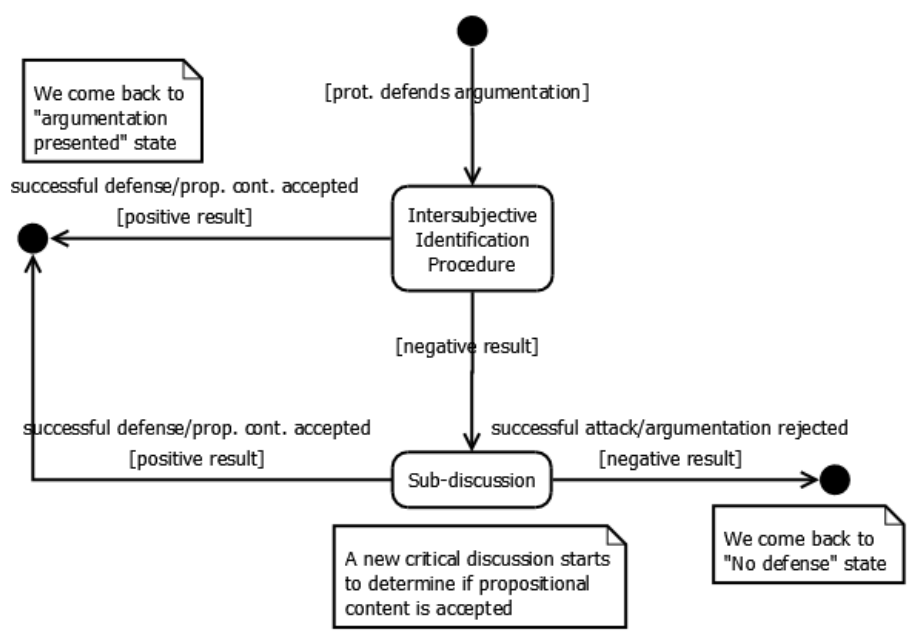

Figure 3: Defense of the propositional content of an argument

${ }^{12}$ In these diagrams, text over the arrows without brackets tells us about the effect of the transition.

(C) Alejandro Secades. Informal Logic, Vol. 35, No. 3 (2015), pp. 342-377. 
In order to defend her argumentation against this attack, the protagonist must go to the Intersubjective Identification Procedure. In the Opening Stage, contenders have agreed on (1) a list of propositions that they both accept, and (2) how to accept new information not included in that list (e.g., looking in an encyclopedia or certain manuals or books). In the Intersubjective Identification Procedure, protagonist and antagonist search for the questioned propositional content in the previous list and through the method agreed in the Opening Stage for new information.

If the propositional content questioned is found (positive result), the defense is successful. Otherwise, they would have to start a new critical discussion ${ }^{13}$, called sub-discussion, to test whether that propositional content must be accepted or not. A sub-discussion is a new critical discussion, run by the same rules. The only difference is that the standpoint to be defended or attacked will be the propositional content questioned by the antagonist in the main discussion. This simple mechanism allows critical discussions to be nested in a process that is recursive in nature. The sub-discussion will have a positive or negative result; accordingly, the propositional content will be successfully attacked or defended.

According to Pragma-dialectics, any argument can consist of more than one proposition. Rule 7 does not make clear whether the antagonist must question the whole propositional content of the argument or she can question different parts of it in several attacks. Whatever the case, our diagram allows both possibilities.

The other possible type of attack questions the force of justification or refutation of the argument (rule 8). It is modeled in Figure 4 on the next page. According to Pragma-dialectics, when the argumentation is completely externalized ${ }^{14}$, its soundness depends on its logical validity. In this case, contenders go to the Intersubjective Inference Procedure. In this procedure, they will test whether or not the inference from the questioned argumentation can be accepted taking into account the inference rules accepted in the discussion (in other words, they will test

${ }^{13}$ In fact, this step is not mandatory. The contenders could have agreed, in the Opening Stage, not to allow a sub-discussion (see comments on rule 7).

14 According to Pragma-dialectics, the reasoning in the argumentation is completely externalized when "the protagonist can be regarded as committed to the claim that the soundness of the argumentation depends on its logical validity (van Eemeren \& Grootendorst, 2004, p. 148). That is, "if the reasoning that is used in the argumentation is expressed in full", so that "it is possible for the antagonists and protagonists to determine whether the standpoints that are defended in a discourse or text do indeed follow logically from the argumentation that is advanced" (2004, p. 194).

(C) Alejandro Secades. Informal Logic, Vol. 35, No. 3 (2015), pp. 342-377. 
the logical validity of the argumentation, the step from premises to conclusion). The result of this procedure will be, as in the previous case, either positive or negative.

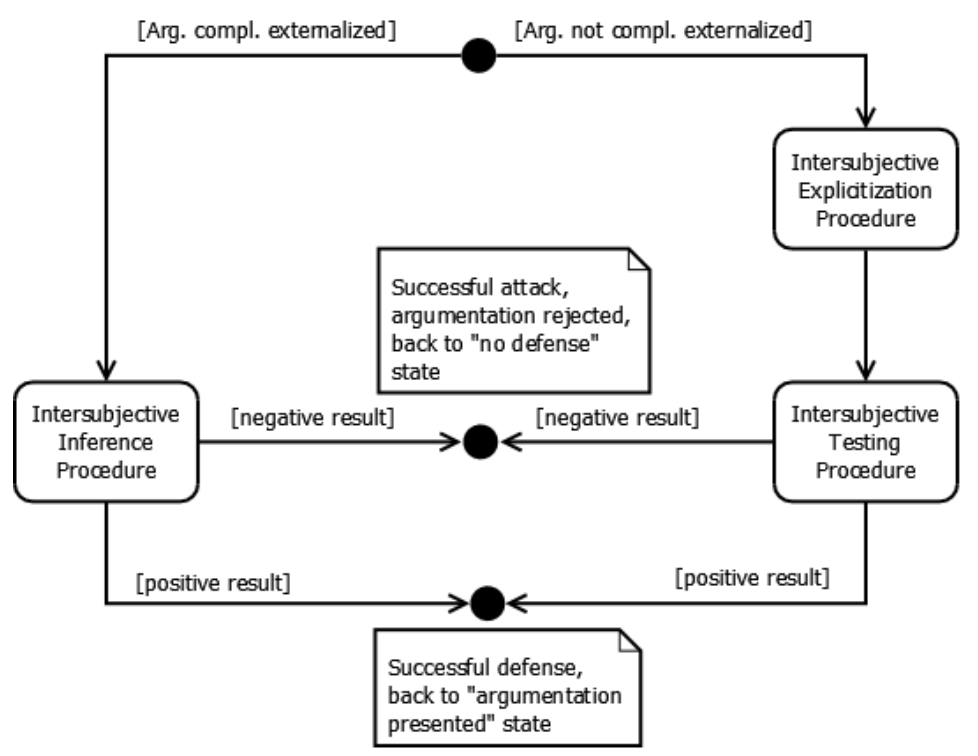

\section{Figure 4: Defense of the force of justification or refutation}

If the argumentation is not completely externalized, contenders have to go to the Intersubjective Explicitization Procedure. The result of this procedure is the layout of the argumentative scheme underlying the argumentation presented. Thus, the Intersubjective Testing Procedure will determine whether such an argumentative scheme is admissible for both contenders and whether or not it has been correctly applied. The result will be, as in previous cases, either positive or negative.

By adding the latter two diagrams to the main one, we get a more detailed model of the Argumentation Stage, Figure 5, which appears on the following page

This diagram, may seem too simple for truly reflecting what a critical discussion is. Of course, the model of a critical discussion, as defined by Pragma-dialectics, has many more items than those included in the previous diagrams (i.e., the types of speech acts involved in each communicative move are not described). Yet, the elements taken on board allow us to visualize the main characteristics of the resolution of a difference of opinion according to Pragma-dialectics. 


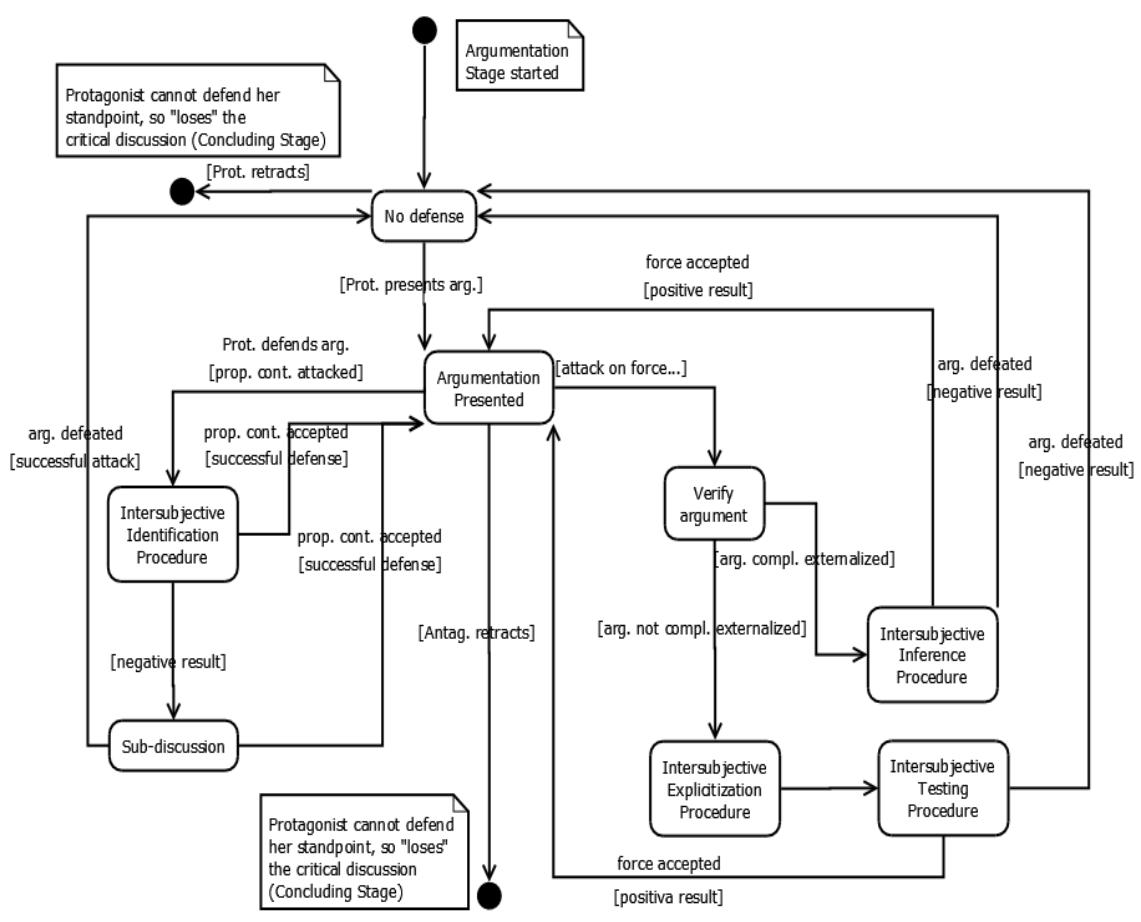

Figure 5: Argumentation Stage complete

This diagram may seem too simple for truly reflecting what a critical discussion is. Of course, the model of a critical discussion, as defined by Pragma-dialectics, has many more items than those included in the previous diagrams (i.e., the types of speech acts involved in each communicative move are not described). Yet, the elements taken on board allow us to visualize the main characteristics of the resolution of a difference of opinion according to Pragma-dialectics.

I have deliberately omitted some aspects of the original description of a critical discussion. The reason is that they make no sense in a formal or computational system. At any rate, they do not affect the analysis I would like to carry on now, and they would make our computational model unnecessary complex. The omitted aspects are the following:

- The stages of a critical discussion can appear disordered or be implicit in a real discussion (van Eemeren \& Grootendorst, 2004, pp. 59-60). I have assumed that they appear in the natural order proposed by Pragmadialectics.

- Usage declaratives: according to van Eemeren \& Grootendorst (2004, pp. 66-67) usage declaratives are the only declarative speech acts that play a role in the critical discussion. This role is "...to enlarge or facili- 
tate the listener's or reader's understanding of other speech acts. The speaker or writer performs them in a critical discussion to make clear how a particular speech act is to be interpreted" (van Eemeren \& Grootendorst, 2004, p. 66). Yet, I have assumed that communication takes place by means of a formal language and a formal semantics, so that ambiguity issues, which are characteristic of natural languages, do not arise. Thus, in principle, there would be no need for usage declaratives, since there is no need for clarifying the interpretation of speech acts ${ }^{15}$.

- Finally, I have not explicitly modeled the fact that speech acts cannot be repeated with the same purpose in a discussion ${ }^{16}$, which is part of rule 13 (van Eemeren \& Grootendorst, 2004, p. 154). Rather, I have considered it a general property of the computational $\operatorname{model}^{17}$.

Besides, a closer examination of our explanation of the computational model shows that there are some rules that have not been explicitly mentioned. They are the following:

- Rule 1 establishes the "freedom" of the opponents to make any move (within the rules). This possibility is implicit in our computational model.

- Rule 11 sanctions the right of the protagonist to defend her presented arguments, which is also implicit in our model.

- Rule 13 has three parts: (a), prohibiting the repetition of the same dialectical move, which is assumed as a general feature of the system, as already pointed out. And (b) and (c) establishing that each contender must

${ }^{15}$ Of course, we might have considered a computational system involving non-formal communication. In that case, the main properties of the model would not have been affected; we would merely have had to introduce some extra features.

${ }^{16}$ Among other things, this prevents opponents from turning a critical discussion into an infinite process -for example, by questioning over and over again one aspect of the same argument that has been already successfully defended by the other participant.

17 This a common practice in software engineering. The reason is that introducing these kind of rules in the diagrams would make them unnecessary complex (it would be harder to understand and, even, recognise the otherand more important - features of the computational model). Of course, if we want to build software implementing the computational model, the rule will have to be programmed. 
in turn make a move, and only one move at one time. This is also implicit in our model.

- Rule 15 is about usage declaratives, which are not included in this computational model, as explained above.

- Finally, rule 5 states that, prior to the Argumentation Stage, in the Opening Stage, rules should be set to define (1) how to attack and defend the standpoint and (2) when attacks or defenses are successful. Precisely, one of the things we are going to consider in the following sections is the relevance of this rule.

\section{A limitation of the critical discussion? How to attack a standpoint}

By considering the above diagrams, we can discover a peculiar feature of the model of a critical discussion.

According to Pragma-dialectics, the burden of proof rests solely on the protagonist, as this is the only party that must defend her standpoint. In order to do so, she must present arguments that, in turn, can be questioned by the antagonist. And that is all: the protagonist presents arguments, the antagonist attacks them and the protagonist defends them. The antagonist can only question the arguments presented by the protagonist. She cannot present an argument to show that the standpoint of the protagonist is not valid or acceptable. This feature of the critical discussion, as characterized by the 15 rules, has important consequences that become evident in our computational model: once the Argumentation Stage has started (so that the protagonist and antagonist roles have been already assigned), the antagonist cannot present an argument to refute the protagonist's standpoint, even if there is a valid argument available for that.

However, it seems to be a normal practice in actual argumentative discussions that any party can directly attack the standpoint defended by the other, rather than just wait for her arguments and decide whether she questions them or not. So, how should we proceed if, while reconstructing actual argumentation, we find that the antagonist presents an argument against the standpoint defended by the protagonist?

Pragma-dialectics can manage that situation in two ways:

(a) On the one hand, we can interchange the roles of protagonist and antagonist in the Opening Stage, taking as a new 
standpoint the previous one, now denied ${ }^{18}$. This way, the former antagonist, now protagonist, may present arguments defending the denial of the original standpoint (defending, in fact, the new standpoint). However, this solution has a problem: in the new situation, the antagonist (former protagonist) cannot present any argument. Therefore, there is a basic limitation ${ }^{19}$ : the model of a critical discussion, as described by its 15 rules, seems to allow only one contender (the protagonist) to present arguments. But, in actual argumentation, it is very common to see both contenders presenting arguments.

(b) On the other hand, Pragma-dialectics offers a solution when both contenders present arguments. The critical discussion described by 15 rules, as we have seen, is for a single, nonmixed difference of opinion. But if we find that both contenders wish to present arguments, we must turn the difference of opinion into a mixed one. In this case, a contender has a point of view about a proposition $p$, while the other defends the contradictory point of view about $p$. The way to deal with such a difference of opinion is to consider two simultaneous critical discussions, both non-mixed. One of them with protagonist $A$, antagonist $B$ and standpoint $S$, and the other with protagonist $B$, antagonist $A$ and standpoint not- $S^{20}$. Thus, we have to build two critical discussions, each of them reflecting different moves of the actual argumentative discourse.

Yet, there is also a difficulty with this solution. As shown in diagram 3, if the Intersubjective Identification Procedure finishes with a negative result, a sub-discussion should start. This sub-discussion must be a non-mixed one, since the antagonist defends a standpoint $T$ (the propositional content under attack in the main discussion) and the antagonist questions it (see comments on rule 7). But, if the antagonist wishes to attack that propositional content with an argument refuting it, the problem arises again. We cannot interchange protagonist and antagonist rules, as seen in solution (a), because, according to rule 7 , the

\footnotetext{
${ }^{18}$ A standpoint is a point of view about a proposition, so "standpoint denied" means, here, that the new standpoint is contradictory to the original: if we are committed to accept one of them, then we are committed to reject the other.

${ }^{19}$ We can see that there is also a practical problem: we have to review all the argumentative exchange in order to properly assign protagonist and antagonist roles, no matter who presented the standpoint and who questioned it at the beginning of the "actual" argumentation. Furthermore, if we wished to use the model of a critical discussion as a guide to produce (build) good argumentative discourse, it would not be easy to know, in the Opening Stage, which contender has the better argument, in order to assign her the role of protagonist.

20 "Not-S" means, in this context, "S denied", see footnote 18.
} 
roles should remain the same in the sub-discussion. And we cannot turn the sub-discussion's difference of opinion into a mixed one (b solution), because rule 7 establishes that it must be non-mixed. Finally, there is a practical problem if we turn the difference of opinion into a mixed one: we would have to deal with two different critical discussions at the same time, with the same contenders in different roles and the same propositional content for both standpoints but contradictory points of view about them. The process of reconstructing the critical discussions would be much more complex than to deal with a single, non-mixed difference of opinion ${ }^{21}$. Pragma-dialecticians can argue that avoiding complexity is not one of their goals, but we can find that, most of the time, the model of a critical discussion, designed for a non-mixed difference of opinion, does not fit with actual argumentation, and we will be forced to turn the difference of opinion into a mixed-one, which is much harder to deal with.

In conclusion, we have found two problems as a result of our analysis:

(1) Sub-discussions must be non-mixed (rule 7), but nonmixed differences of opinion do not allow the antagonist to attack the standpoint with an argument.

(2) It is expected that most argumentative discourses will have to be analyzed as mixed differences of opinion. But it is much harder to deal with a mixed difference of opinion than a non-mixed one. This is a practical issue, rather than theoretical.

The first problem is more important, since it is a limitation of the model of a critical discussion. Anyway, I think that we can improve the model of a critical discussion proposed by Pragma-dialectics and solve both problems, if we change the rules in order to allow for the antagonist to raise an argument supporting her questioning of the standpoint. Such change would have little impact in the foundations of Pragma-dialectics, but it would make the basic model of a critical discussion easier and more intuitive to apply. At the same time it would resolve the sub-discussion issue (1). We just need to allow for the an-

21 The problem would be even bigger if we wished to use the model of a critical discussion as a guide to produce (build) good argumentative discourse, because it would force us to deal with two concurrent critical discussions, and simultaneity is hard to manage, both on computational or "manual" processes.

(C) Alejandro Secades. Informal Logic, Vol. 35, No. 3 (2015), pp. 342-377. 
tagonist to raise an argument "attacking" the standpoint. That argument could be defended and questioned in the same way as Pragma-dialectics prescribes for arguments presented by the protagonist (roles interchanged). The only difference is that if such an attack is defended successfully, the protagonist will have to retract her standpoint, and if the antagonist's attack is in turn attacked successfully, the critical discussion will return to the "No defense" state. The next diagram shows diagram 2 modified so as to allow the antagonist attacking the standpoint. New states and transitions are inside a blue square for a better identification (for simplicity sake, I have omitted the labels on transitions):

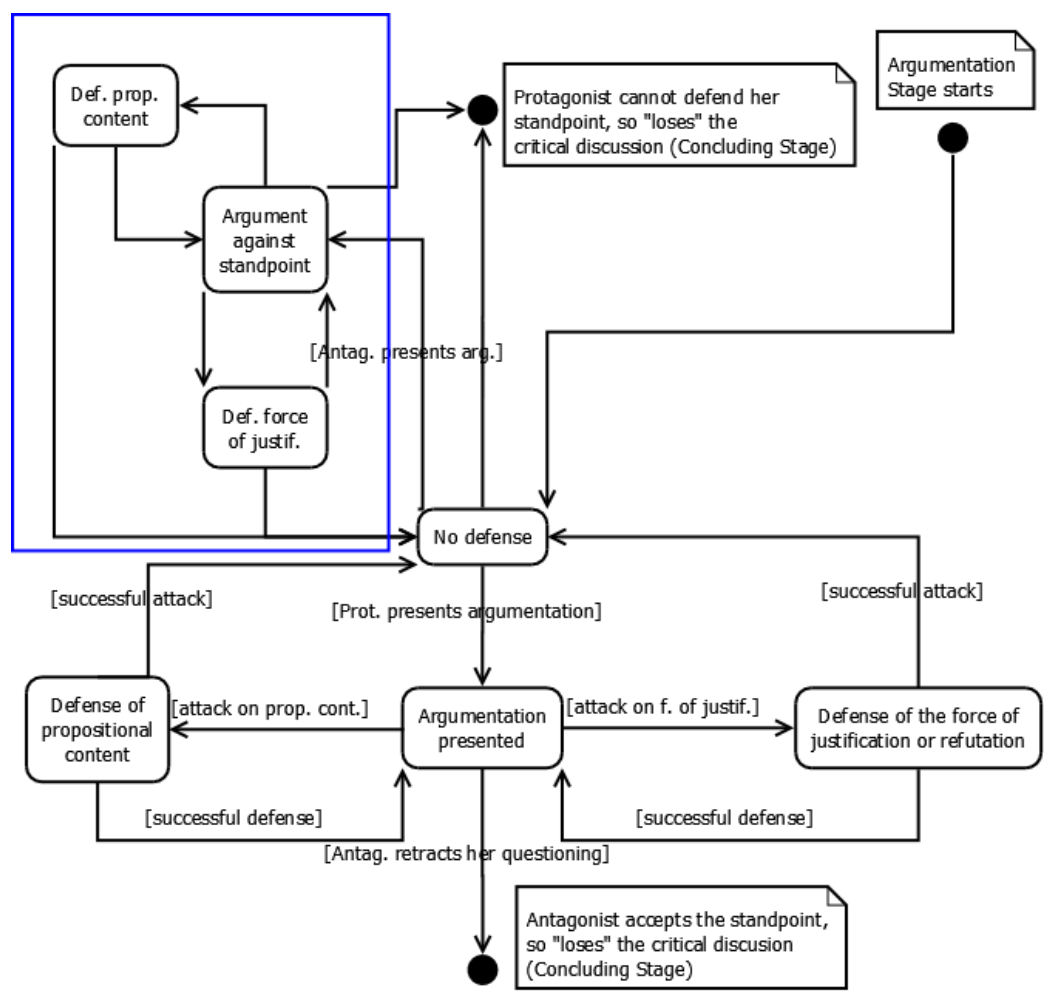

Figure 6: Critical discussion modified (antagonist can attack the standpoint)

In order to understand diagram 6 , it is important to consider that:

1. The difference of opinion is still a single, non-mixed one (a mixed one would require two critical discussions). But we could consider that the new diagram can manage mixed ones, too.

2. In the "no defense" state, both protagonist and antagonist can present an argument. It could be the case that 
both contenders have a "winning" argument, so the first who presents it would "win". We can consider that they can present arguments in turn, and that the protagonist plays first. This simple solution is consistent with the discussion about the burden of proof (cf. van Eemeren \& Grootendorst, 2004, pp. 140-141)

This diagram is just a suggestion and it implies some changes in the rules for a critical discussion. There can be other ways to deal with the situation described in this section.

\section{The model of reasoning in Pragma-dialectics}

One of the most notable features of Pragma-dialectics is, in my opinion, that it leaves almost entirely undefined what we might call, following Bermejo-Luque (2011), the "logical dimension of argumentation" 22 . This becomes even more evident in the computational model proposed thus far. In the Opening Stage contenders must make explicit the rules to decide (a) how to determine logical validity of an argument or inference ${ }^{23}$ and (b) which argumentative schemes are admissible and how to determine whether or not they have been correctly applied. Some remarks can be made in this regard.

First, we can conclude that Pragma-dialectics is not committed to any particular model of reasoning/inference. Presumably, this is right for the authors: the model of a critical discussion aims to evaluate/analyze argumentative discourses, not arguments. Consequently, the rules to evaluate arguments can be decided in the Opening Stage of each critical discussion. But, is the model of a critical discussion completely indifferent to the model of reasoning/inference chosen? It is not clear, at least in principle, that the model works equally well with whatever model of reasoning/inference we choose. Accordingly, it is interesting to test how it works with some of the different models

\footnotetext{
22 The other two dimensions of argumentation would be the dialectical and the rhetorical. Pragma-dialectics is clearly focused on the dialectical one. An account of the rhetorical dimension of argumentation was introduced in Pragma-dialectics later, with the concept of strategic manoeuvring, cf. (van Eemeren, 2012) for an introduction.

${ }^{23}$ Strictly, arguments and inferences are not the same. In Pragma-dialectics, an argument involves an inference, but arguments, contrary to inferences, are speech-acts. However, in Artificial Intelligence and Logic is very common to identify inferences and arguments, because only the inferential structure of arguments is taken into account, leaving aside other dimensions of argumentation as a communicative practice.
}

(C) Alejandro Secades. Informal Logic, Vol. 35, No. 3 (2015), pp. 342-377. 
of reasoning proposed by Philosophy, Logic or Artificial Intelligence. This is the goal of the following sections.

For now, we will focus on the few things that van Eemeren and Grootendorst (2004) say about reasoning and inference. According to Pragma-dialectics, there are two kinds of arguments: those which are completely externalized and those which are not (cf. diagram 4).

If an argument is completely externalized, we may directly proceed to check its logical validity. It seems that the authors think of some (formal?) logic system as the basis for the Intersubjective Inference Procedure (dialogue rules from Erlangen School are the cited example, p. 148). In turn, if the argument is not completely externalized, the process is different: we have to get the underlying argumentative scheme (Intersubjective Explicitization Procedure) and, then, test it (Intersubjective Testing Procedure).

At this point, we can raise the following question: Why can't we just "externalize" the argument and, then, apply the Intersubjective Inference Procedure? The model would be simpler. However, it seems that van Eemeren and Grootendorst consider that there are arguments that cannot be "completely externalized" at all, whatever the logical system we choose for checking their logical validity. I think that some logicians and philosophers would not agree, so perhaps this position needs further analysis.

On the other hand, maybe van Eemeren and Grootendorst just tried to underline the difference between deductive reasoning (i.e., logically valid) and non-deductive reasoning (that is, reasoning whose validity must be determine by means of argumentative schemes). But, why argumentative schemes? There are other ways to appraise non-deductive reasoning.

In any case, Pragma-dialectics is meant to leave the contenders free to choose whatever model of reasoning/inference they agree on at the Opening Stage. But, at the same time, the model of a critical discussion is committed to some particular points of view about reasoning and inference. In my view, all this shows is that Pragma-dialectics should pay more attention to the "logical dimension of argumentation" in order to improve the model of a critical discussion. In order to make clear in which way the model of a critical discussion interferes with the model of reasoning/inference chosen by the parties, in the next sections I analyze the functioning of our computational model of a critical discussion with some reasoning/inference models widely used. 


\section{Classical formal logic as the model of reasoning/inference ${ }^{24}$}

As pointed out in the previous section, Pragma-dialectics leaves almost undefined the "logical dimension of argumentation". Rather, according to the model of a critical discussion, this is something to be determined in the Opening Stage of each particular argumentative exchange: it is contenders who must agree on a particular set of inference rules or argumentative schemas to be used. Now, I am going to analyze what happens when contenders decide to employ classical formal logic as the model of reasoning/inference. I will start with propositional logic and, then, I will increase complexity step by step.

\subsection{Case 1: Propositional logic and knowledge base established in the Opening Stage}

The first case to be considered is a common reasoning/inference scheme in Artificial Intelligence. In the Opening Stage, contenders agree that the model for reasoning/inference will be classical propositional logic. Accordingly, they agree that:

1. The standpoint will be expressed as a propositional formula $p$. The protagonist defends $p$ and the antagonist questions $\mathrm{it}^{25}$ (we assume that the difference of opinion is single non-mixed).

2. Contenders establish a finite set or list of propositions/formulae accepted by both of them. According to Artificial Intelligence usages, we can take this list to be the knowledge base and represent it by $\Delta$. There cannot be incoherencies in $\Delta$.

3. $\Delta$ cannot change in the Argumentation Stage.

4. There are no other sources of information, the Intersubjective Identification Procedure will just search in $\Delta$.

24 "Classical formal logic" refers, in this section, to either propositional or first-order.

${ }^{25}$ A standpoint is a point of view about a proposition, as we have seen. But in this particular case (classical propositional logic), the protagonist can just defend that the proposition is true or false. But defending that a proposition $p$ is false is the same that defending that $\neg p$ is true. So, for simplicity sake, we can consider that the protagonist always defends that a propositional formula $p$ is true (no matters the composition of that formula), and the antagonist questions it.

(C) Alejandro Secades. Informal Logic, Vol. 35, No. 3 (2015), pp. 342-377. 
In this scheme, an argument is a pair $(\phi, \alpha)$, where $\phi \vdash \alpha(\phi$ are premises ${ }^{26}$, and $\alpha$ is the standpoint supported by the argument $^{27}$ ).

Now, we can take a look at the computational model built in section 2 .

Once the protagonist presents an argument, the antagonist can attack either its propositional content or its force of justification.

(a) If the antagonist attacks the propositional content of the argument, the Intersubjective Identification Procedure will simply look for $\phi$ in the knowledge base $\Delta$. If it is not found, a new sub-discussion will be raised. The sub-discussion will try to decide whether or not $\phi$ can be deduced from $\Delta$. Rules, knowledge base and roles remain the same, but the standpoint is now $\phi$.

(b) If the force of justification or refutation ${ }^{28}$ of the argument is attacked, we can notice that every argument presented will be completely externalized. The reason is that an argument, in this situation, is just a logical deduction. Therefore, we do not need either an Intersubjective Explicitization Procedure or an Intersubjective Testing Procedure. All we have to do is to test the logical validity of the argument, which is made in the Intersubjective Inference Procedure. Propositional logic offers several well-known ways to do this, based either on natural deduction or in automatic procedures.

At this point, the model of a critical discussion, using propositional logic and a previously established knowledge base, remains as follows (I have changed some names of processes and transitions to better reflect the key issues of this case):

\footnotetext{
${ }^{26}$ We can consider that $\phi$ is formed by several premises $\left(\phi_{1}, \phi_{2} \ldots, \phi_{\mathrm{n}}\right)$, so that they can be attacked one by one. The computational model allows attacks both on $\phi$ as a whole $\left(\phi_{1} \wedge \phi_{2} \wedge \ldots \wedge \phi_{n}\right)$ or on a part of $\phi\left(\phi_{i}\right)$, as we have seen (see p. 6).

${ }_{27}$ According to Pragma-dialectics, the conclusion is not part of the argument, as we have seen. But, since we are dealing with formal logic, in this section I will include the conclusion, for clarity.

${ }^{28}$ For the rest of the paper, I will omit "or refutation", for the sake of simplicity.
}

(C) Alejandro Secades. Informal Logic, Vol. 35, No. 3 (2015), pp. 342-377. 


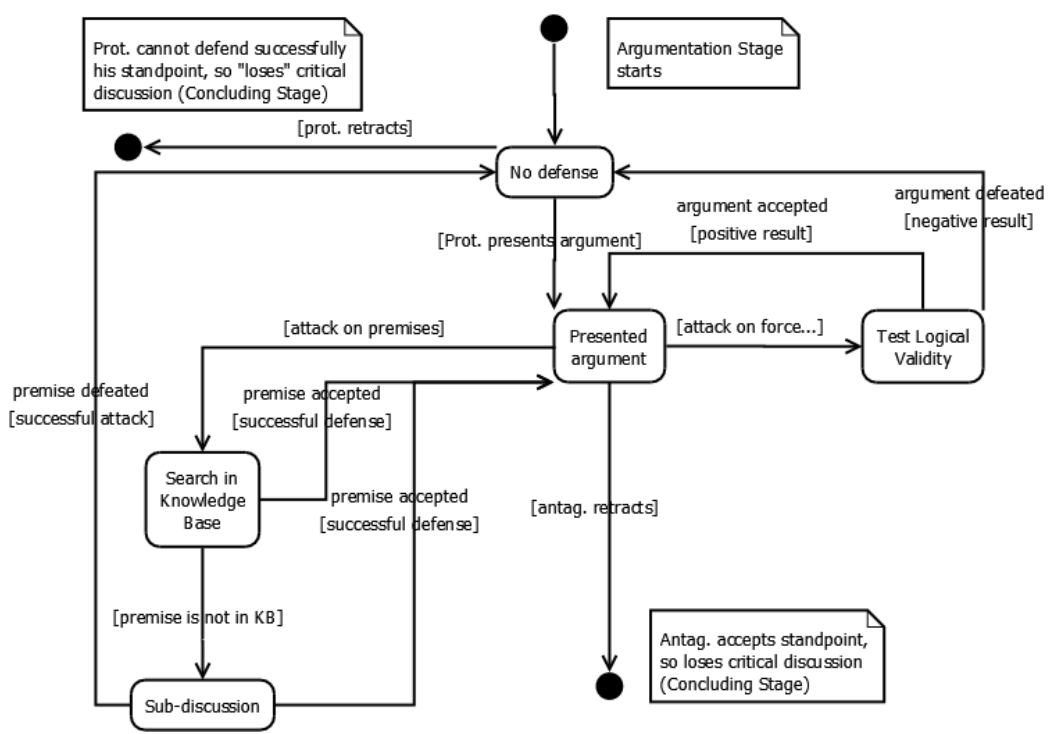

Figure 7: Propositional logic and knowledge base established in the Opening Stage

What follows is a simple example of how a critical discussion can proceed in this case:

Two agents decide to start a critical discussion about standpoint r (Confrontation Stage). In the Opening Stage they agree that $\Delta$ will be $\{\mathrm{p}, \mathrm{p} \rightarrow \mathrm{q}, \mathrm{q} \rightarrow \mathrm{r}, \ldots\}$, and that they will use Gentzen's inference rules ${ }^{29}$ for the Intersubjective Inference Procedure ("Test Logical Validity" state).

In the Argumentation Stage, they make the following moves:

1. The protagonist presents an argument (deduction): $\{\mathrm{q}$, $\mathrm{q} \rightarrow \mathrm{r} \vdash \mathrm{r}\}$

2. The antagonist attacks the force of justification of the argument, so they move on to the Intersubjective Inference Procedure in order to test whether the argument's logical form matches one of the accepted inference rules

3. The logical form of the argument matches with Modus Ponens rule (elimination of implication in Gentzen's system); therefore, the force of justification of the argument is accepted

${ }^{29}$ Gentzen's eight inference rules are, perhaps, the most popular way to deal with propositional logic in a natural deduction environment, and they are easy to use, see (Garrido, 2001, pp. $87 \mathrm{ff}$.).

(C) Alejandro Secades. Informal Logic, Vol. 35, No. 3 (2015), pp. 342-377. 
4. The antagonist may then attack the propositional content of the argument (the premises). That is, $\{\mathrm{q} \rightarrow \mathrm{r}\}$ is in $\Delta$, so let us suppose that she attacks the other premise, $\{\mathrm{q}\}$

5. The Intersubjective Identification Procedure is not successful ( $\{\mathrm{q}\}$ is not found in $\Delta$ ), so a new sub-discussion is raised, with standpoint q:

a. The protagonist presents an argument: $\{\mathrm{p}, \mathrm{p} \rightarrow \mathrm{q}+\mathrm{q}\}$

b. If the antagonist attacks the propositional content of the argument, she will not succeed, because the premises ( $p$ and $p \rightarrow q$ ) belong to $\Delta$

c. If the antagonist attacks the force of justification of the argument, she will not succeed, because the logical form of the argument is accepted (see step 4)

d. The antagonist must retract her questioning of the argument and must accept it, since she cannot attack it successfully

6. The sub-discussion brings a positive result; therefore the protagonist has defended successfully her argument. Since the antagonist cannot make more attacks on the argument (see steps 2 and 3), she must retract her questioning of the argument and accept it

7. Therefore, the antagonist accepts standpoint $r$ (the protagonist "wins" the critical discussion).

Some comments can be made about the diagram and the above example. Firstly, we can notice that the argumentation must be presented in "reverse" order, from conclusion to premises. The protagonist must present a logically valid argument whose conclusion is the standpoint. Then, if the premises are not in $\Delta$, a sub-discussion must begin. The process will go on until the protagonist can present a logically valid argument whose premises are in $\Delta$. Sometimes, actual argumentation can proceed in this way, but at other times, actual arguers proceed in different ways, (e.g., chaining several arguments from premises to conclusion, or presenting arguments to support an intermediary conclusion used to support the standpoint). In this case, it can be hard to build the critical discussion from actual argumentation in order to evaluate it, because the critical discussion reconstructed can have a very different structure from the original discussion. Anyway, this is not a theoretical problem. It can be a practical one, making it hard to make actual argumentation fit the model of a critical discussion, as proposed by Pragma-dialectics.

Secondly, in the Opening Stage, contenders decided to employ Gentzen's inference rules in order to test the logical validity of an argument. Yet, there are other options available. 
Propositional logic is consistent, complete and decidable, so they can decide to employ any decidable procedure to test logical validity. In this case, when a premise is not found in $\Delta$, they do not need to start a sub-discussion: they just have to apply any decidable procedure (e.g., truth tables) to see whether that premise can be logically deduced from $\Delta$. This is the same for the Intersubjective Inference Procedure: they just need to apply the same procedure to the whole argument (the logical deduction). But, in this case, our model turns into a much simpler one: the protagonist presents an argument whose conclusion is $p$, and contenders just have to test whether the argument can be deduced from $\Delta$. In fact, the protagonist does not need to present any argument: contenders just have to verify whether or not $p$ can be deduced from $\Delta$.

In conclusion, in the scheme presented, the Argumentation Stage can be reduced to any decidable procedure to test whether the standpoint can be logically deduced from $\Delta$. Accordingly, in a situation in which contenders have agreed to follow propositional logic as their model of reasoning, we would not need to reconstruct the Argumentation Stage in order to evaluate an actual piece of argumentation as an attempt to resolve a difference of opinion $^{30}$. As a consequence, the need to endorse an important part of the critical discussion (namely, the Argumentation Stage) as a means to determine argumentation goodness would seem to lose ground.

\subsection{Case 2: Predicate Logic}

We can decide to use first-order logic (predicate logic) instead of propositional logic, while maintaining the rest of the scheme. Can it make a difference?

Predicate logic is consistent and complete, but it is not decidable. However, there are certain cases where predicate logic is decidable (Garrido, 2001, p. 237). If we decide to employ any decidable subset of first-order logic ${ }^{31}$, everything we said for case 1 (propositional logic) will remain the same. Otherwise, contenders will not have an algorithm or procedure available to

${ }^{30} \mathrm{We}$ just have to reconstruct the Confrontation Stage and the Opening Stage (standpoint, roles and knowledge base) and, then, see whether the standpoint can be deduced (it can be made with truth-tables, natural deduction or other method available.). This is a faster and safer method to test argument goodness than reconstructing a whole Argumentation Stage. Of course, we can reconstruct the Argumentation Stage for other reasons, but if we just want to see which contender is right, we don't have to.

${ }^{31}$ Many Artificial Intelligence applications do that, like those based in programming logic (e.g., PROLOG uses only Horn clauses).

(C) Alejandro Secades. Informal Logic, Vol. 35, No. 3 (2015), pp. 342-377. 
test, in a finite time, whether a particular standpoint can be deduced from the knowledge base or not. Therefore, they will not be able to simplify the Argumentation Stage as we saw in the second comment of case $1^{32}$. In this case, the Argumentation Stage will be developed as in the example in case 1 .

\subsection{Case 3: Classical formal logic with $\Delta$ growing dynamically}

We can extend our model by allowing $\Delta$ to grow in the Argumentation Stage. This means that in the Intersubjective Identification Procedure we can accept propositional contents not previously listed in the Opening Stage. This situation is allowed by the rules for the critical discussion, as we have seen, previously, in the explanation of diagram 3. Actually, it makes sense to deal with this possibility when considering actual argumentation. For example, in legal argumentation, we do not need to check, in the Opening Stage, every precedent related to the case. In fact, that would be impossible. Rather, it is in the Argumentation Stage where, if the protagonist presents an argument based in an unknown precedent, that the contenders would have to look for it (by means of the Intersubjective Identification Procedure). If the precedent is found, it will be added to the list of accepted premises.

Classical logic (propositional or first-order) is monotonic. Thus, new information cannot introduce incoherency in $\Delta$ (i.e., if $p$ is deductible in $\Delta$, we cannot add $\neg p$ to $\Delta$ because $p$ and $\neg p$ are inconsistent). Therefore, new content can be useful only if we cannot find in $\Delta$ any argument that either defends $\mathrm{p}$ successfully or defends the denial of $p$ ( $\neg p$ in propositional logic). If there is already an argument that defends $p$ successfully, new content cannot change anything (the protagonist will "win" if she presents this argument). If there is already an argument that defends successfully $\neg p$, the protagonist will never find in new content an argument that could defend $p$ successfully (that would introduce incoherency in $\Delta$ ).

Anyway, the computational model remains the same as in case 1 (diagram 7). The only difference is that in the state labelled "Search in the knowledge base", contenders will look for propositional content both in $\Delta$ and in the external sources agreed in the Opening Stage (we can consider $\Delta$ and those external sources as an "extended- $\Delta$ ").

32 Anyway, formal logic and Artificial Intelligence offer several approaches to test logical validity that could be used instead, although they are not decidable algorithms.

(C) Alejandro Secades. Informal Logic, Vol. 35, No. 3 (2015), pp. 342-377. 
In conclusion, everything we said about case 1 and 2 remains the same for case 3 .

\section{Defeasible reasoning}

In the last section, I have followed our computational model of a critical discussion in order to analyze what happens when contenders decide to employ classical (monotonic) formal logic as the underlying model of reasoning/inference. No doubt, there are many other formal systems, like some modal logics (extended logics) or fuzzy logic (an alternative logic) that we might also have taken into account. However, if the chosen formalism is still monotonic, the results will remain quite the same.

Alternatively, contenders can implement a critical discussion with a non-monotonic model of reasoning. Defeasible logic is non-monotonic and is broadly used in Artificial Intelligence and, especially, in Computational Argumentation. It also fits well with intuitive notions of argumentation.

Broadly, defeasible reasoning can be defined as reasoning that is rationally compelling but not deductively valid (Koons, 2013). However, the actual scope of defeasible reasoning is usually reduced to reasoning where an accepted inference can be defeated in the face of new information. From a logical point of view, that makes defeasible reasoning non-monotonic ${ }^{33}$, which means that, if we add information to the knowledge base, the set of valid deductions can decrease. This is related with another feature of defeasible reasoning: it can manage logical incoherencies. Most actual reasoning is defeasible: we accept inferences as correct which, later, we revise in the face of new information; we deal with incoherencies as part of normal reasoning; we present arguments that defeat those presented by our contenders, who can present other arguments to defeat ours, and so on.

There are many formalisms or "logics" that try to model defeasible or non-monotonic reasoning ${ }^{34}$. In this section I will start with defeasible reasoning in a general way, although I will focus on the most usual models in Computational Argumentation.

\footnotetext{
33 In fact, sometimes both concepts are taken to be equivalent (e.g., see Antonelli, 2012).

${ }^{34}$ See Antonelli (2012) and Koons (2013) for an overview of the most classical ones.
} 


\subsection{General features of defeasible logics}

One of the most remarkable features of defeasible systems is that they can deal with incoherencies in the set of accepted premises. However, the form of the accepted contradictions or incoherencies is not, usually, arbitrary. For example, a defeasible system can accept inferences and, at the same time, exceptions to those inferences. The inference will work unless the exception occurs: a conclusion can be accepted provisionally, but, in the face of new information (the exception occurs), it can be rejected.

In Computational Argumentation, the most usual way to deal with these situations is with the concept of attack. An inference can be questioned by an attack. There are two main types of attacks: rebuttals, which question the conclusion of the attacked inference, and undercuts, which question the inference itself or its premises (it depends on the system). An attack can be an inference or formula from the knowledge base, or a special item (i.e., an exception attached to the inference attacked). Finally, it is also common to allow for "strict" knowledge, which cannot be attacked. The idea of a "strict" knowledge makes sense, since it is usual, in everyday argumentation, to have a common ground that cannot be questioned (actually, that common ground is a requirement in Pragma-dialectics).

Accordingly, the process to evaluate an inference involving defeasible reasoning will be quite different from the process employed when using classical logic. In (monotonic) nondefeasible reasoning (e.g., propositional logic), we can accept the conclusion of an actual inference if the premises are accepted by both contenders and we can find an accepted inference rule that matches it. But with defeasible reasoning, this is not enough, because of the possibility of attacks (rebuttals or undercuts): for an attack can "defeat" a previously valid inference (it can defeat the conclusion, the inference rule or the premises). So, in order to evaluate an inference, we will have to check: (1) premises and inference rules, and (2) possible attacks, which could defeat the inference. Yet, if the attack is an inference itself, it can also be attacked, so that the process is clearly recursive. I will show this with an example:

In the next piece of argumentation, the arguments presented are attacked by other arguments that refute them:

(C) Alejandro Secades. Informal Logic, Vol. 35, No. 3 (2015), pp. 342-377. 
John: Let's play tennis tomorrow. We don't have anything to do and we haven't played tennis for a long time.

Peter: A few days ago, I watched the weather forecast from Internet. It said it will rain tomorrow. The court is outdoors, so we won't be able to play.

John: Long-term weather forecasts from Internet are not reliable, and the sun is shining...

Peter: Last time we decided to play tennis, the sun was shining, but the following day it rained heavily and we could not play.

This is a very simple example. A more realistic scene would involve more than one sequence of argument - attack - attack on the attack... In fact, if we want to model all the relevant information in a situation where defeasible reasoning and attacks are involved, we have to build some kind of graph that models inferences, possible attacks (rebuttals and undercuts), etc., as Pollock (2009, p. 174) does. The following is an example, adopting the inference graphs that Pollock proposes, which represents part of the previous example dialogue:

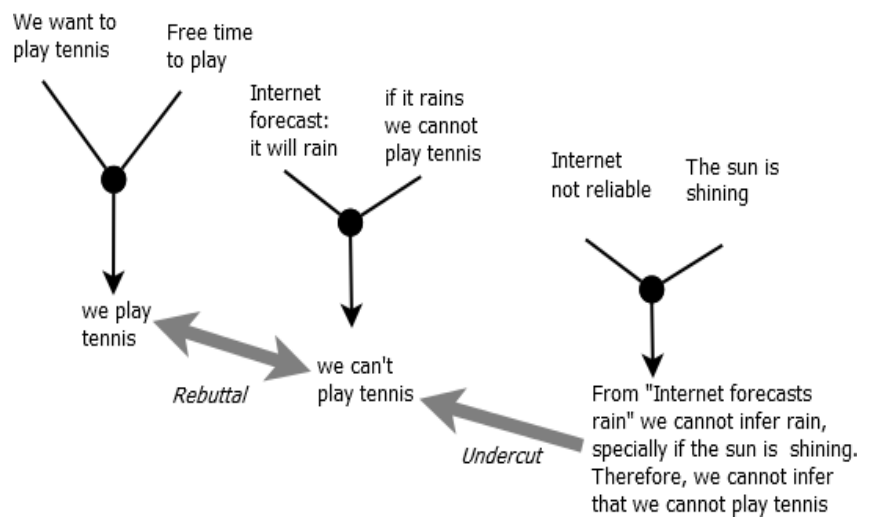

Figure 8: Defeasible reasoning example

Nodes represent valid inferences (the arrow points to the conclusion, the rest are premises). Thick grey arrows represent attacks: rebuttals when they have two directions (the conclusions of the inferences contradict each other) and undercuts when they have one direction (the conclusion of the inference in the start of the arrow refutes the other inference or its premises). A more realistic graph is expected to be much more complex, even involving loops.

Once we have represented the information about inferences and attacks (there are several alternatives to the previous diagram: extensions to formal logic, simpler graphs, etc.), the 
problem is how to decide whether an inference/argument is valid or not. The selected method is usually called semantics (Pollock, 2009 , p. 175). The most usual approach is to consider that an argument is good if it is logically valid and there is no other argument that attacks it or, in case there is, the arguments attacking the previous one are attacked by other good arguments (the process is recursive).

Although there are many proposals to build semantics for defeasible reasoning, most of them involve some kind of tree structure (at least on a conceptual level ${ }^{35}$ ), where the root is the initial argument, its children (nodes) are the arguments attacking the root, which can be attacked by other arguments (the children of these nodes), etc. Of course, such structure does not represent actual argumentation, but all the possible dialectical moves, based on the concept of attack. The following is a simple example where arguments are presented in an informal way and the kind of attack is not defined (not to be confused with example in diagram 8 , the attacks are different):

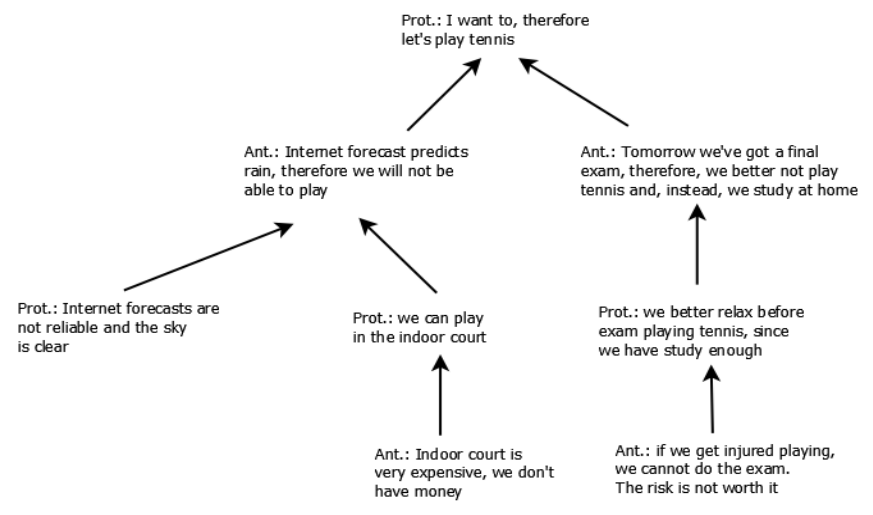

Figure 9: Argumentation tree example

As already pointed out, there are many ways to model defeasible reasoning. The previous examples are in line with recent developments in Computational Argumentation: Pollock (2009) proposes simple recursive semantics to evaluate arguments. García, Dix and Simari (2009) develop an approach based on logic programming while discussing alternatives and extensions (e.g., to add priorities to inference rules and different levels among facts in order to resolve conflicts and loops).

${ }^{35}$ In fact, many semantics for defeasible reasoning try to prune the tree, in order to improve efficiency in evaluating arguments. They have to propose a solution for loops, too (an argument attacks another that attacks the first, perhaps by means of other arguments).

(C) Alejandro Secades. Informal Logic, Vol. 35, No. 3 (2015), pp. 342-377. 
Besnard and Hunter (2009) employ formal logic, but they allow for incoherencies in the knowledge base (an argument is simply a logical deduction whose conclusion can attack other arguments), and they propose a rather simple method to evaluate arguments. Of course, there are viable alternative views, but the one outlined above seems to me the most appropriate to work with Pragma-dialectics, because of its dialectical and algorithmic nature, and because its underlying notion of argument is rather compatible with Pragma-dialectics'. So I will consider that arguments/inferences can be attacked by other arguments that can be attacked, too. A contender will "win" the critical discussion if she can present a valid argument and she can defend it from any attack ${ }^{36}$.

Now, we can analyze how our computational model of a critical discussion works if we implement it with this defeasible reasoning model. But, first, we have to consider whether pragma-dialectical rules may accept defeasible reasoning.

\subsection{Pragma-dialectics and the possibility of logical inconsistencies}

The cases already analyzed (1, 2 and 3 ) were based in monotonic reasoning; so, we admitted no inconsistencies in the knowledge base. This is in line with the model of a critical discussion, as proposed by Pragma-dialectics, which says the following about the knowledge base (the list of propositions accepted in the Opening Stage):

All the propositions that are accepted may be included. The only restriction is that the list must be consistent. It may not contain any propositions that are inconsistent with other propositions. Otherwise it would always be possible to successfully defend any arbitrary standpoint against an attacker, which inevitably renders the resolution of a difference of opinion impossible (van Eemeren \& Grootendorst, 2004, p. 145).

Contrastingly, in defeasible reasoning, it is possible for two inferences (arguments) to have contradictory conclusions. This seems to violate the pragma-dialectical rules, as we have seen above. However, it does not. Pragma-dialectics just wants to guarantee, in the Opening Stage, a minimal rational confidence in the possibility of resolving a difference of opinion. To

\footnotetext{
${ }^{36}$ For the moment, I will not discuss any particular algorithm for determining whether an argument has been successfully attacked.
}

(C) Alejandro Secades. Informal Logic, Vol. 35, No. 3 (2015), pp. 342-377. 
this end, Pragma-dialectics establishes that we need to have a set of propositions that are consistent and cannot be attacked (called "shared premises", p. 145). But that is the only reason van Eemeren and Grootendorst allege for including this rule. By no means are they talking about the properties of any formal (or informal) logic system. Therefore, it does not matter whether there are other information sources that can be inconsistent (in fact, when we start an argumentation, contradictions are usually expected). Most defeasible logics allow defining strict inferences and facts that cannot be attacked.

In conclusion, I think defeasible reasoning can fit the requirements of Pragma-dialectics, so we can go into our next case study: a critical discussion supplemented with defeasible logic.

\subsection{Case 4: Defeasible reasoning}

In this scene, an argument can be attacked by another argument whose conclusion refutes the conclusion (rebuttal) or the premises $^{37}$ (undercut) of the former, and this process can proceed recursively. A valid argument presented by one of the contenders is successfully attacked by another argument if the other contender cannot present a new successful argument against the attacking argument.

I am not going to deal with implementation details (formal language employed, form of the rules, etc.) in order to focus on the general process. For simplicity sake, I will assume that we have procedures for evaluating (a) propositional content (i.e., looking for premises in a knowledge base) and (b) the force of justification of an argument (i.e., looking for an inference rule that matches with the inference). Of course, they are not enough to evaluate logical validity, because we have to deal with possible attacks that can defeat the inference, no matter whether or not the propositional content and the force of justification are successfully defended. A successful undercut or rebuttal would defeat the attacked argument, just as a successful attack on the propositional content or the force of justification does.

Now we have to embed defeasible reasoning, so characterized, within our computational model of a critical discussion. A first approach is to consider that we do not need to make any

${ }^{37}$ As we have seen, an undercut can attack either the premises or the inference itself (it depends on the defeasible reasoning model chosen). In this case an undercut will be an argument whose conclusion contradicts the premises of the attacked argument. After all, our model of a critical discussion already defines a procedure to question the inference - namely, the attack on the force of justification of the argument.

(C) Alejandro Secades. Informal Logic, Vol. 35, No. 3 (2015), pp. 342-377. 
change in our model. After all, Pragma-dialectics defines some procedures to deal with inferences: the Intersubjective Inference Procedure, the Intersubjective Explicitization Procedure and the Intersubjective Testing Procedure. Since we are working with formal logic, we can consider that arguments will always be completely externalized, as we did in previous cases, so that only the first procedure will be needed. Now, the question is: Can defeasible reasoning (including attacks) be managed in the Intersubjective Inference Procedure? This procedure would have to do the following tasks:

- Test whether the inference itself can be accepted, according to a list of inference rules or any other available way.

- Wait for attacks on the argument (undercuts or rebuttals) presented by the antagonist.

- For each attack (if any), the protagonist should be able to question, in turn, its propositional content or its force of justification (such questioning should be properly dealt with). Moreover, the protagonist should be able to present attacks (undercuts or rebuttals), that can be questioned or attacked by the antagonist, and so on (the process is recursive).

- Finally, the result will be positive if the inference itself is accepted and the attacks are defeated.

However, it is easy to see that this is not realistic. This is so because, on the one hand, the Intersubjective Inference Procedure is not defined to do all the work described above. But more importantly, all the stuff about attacks in defeasible reasoning involves more than just testing whether or not an inference is acceptable (i.e., whether or not it matches a valid inference rule). It requires dialectical moves that can generate more attacks, defenses, sub-discussions and more. It has no sense, from a pragma-dialectical point of view, leaving aside all the argumentative discourse required to do it, since Pragmadialectics is committed to, precisely, "analyzing, evaluating and producing argumentative discourse" (see footnote 3). In fact, dialectical moves related to defeasible reasoning can be even more important (or, at least, more numerous) than those included in our computational model of the Argumentation Stage. In conclusion, we should not expect the Intersubjective Inference Procedure, as portrayed in our computational model of a critical discussion, to properly deal with argumentative discourse involving defeasible reasoning. On the contrary, the model of a 
critical discussion should integrate the characteristic dialectical moves inherent to defeasible reasoning (undercuts and rebuttals) as part of the Argumentation Stage.

So, how can we embed defeasible reasoning (i.e., undercuts and rebuttals) into our model? First of all, we can try to build a basic computational model of defeasible attacks. Then, it will be easier to see how to embed these attacks into our computational model.

Undercuts and rebuttals are arguments presented by the antagonist. We can consider that such attacks can be resolved in a sub-discussion, where roles are interchanged and the standpoint is the undercut or rebuttal itself (which is an argument). We can represent this process in the following diagram:

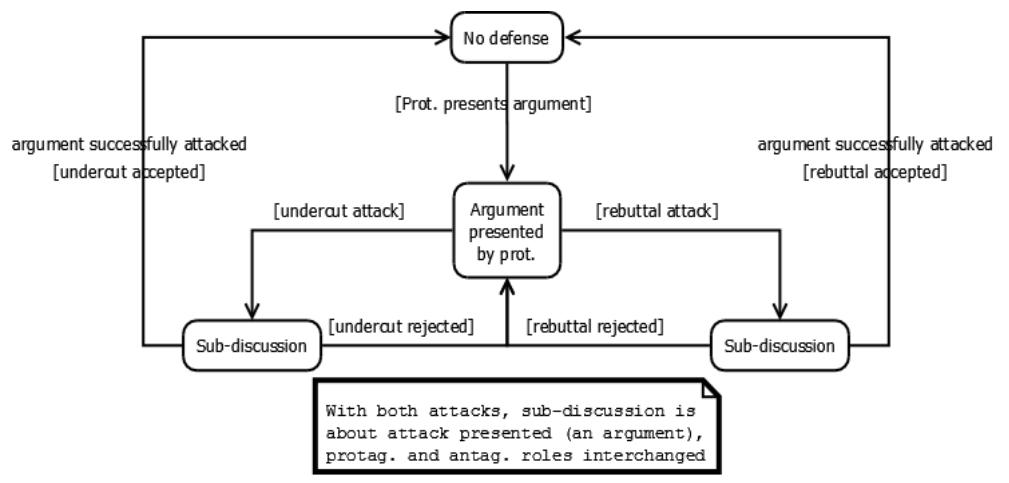

Figure 10: Undercutting and rebutting attacks

At this point, before discussing how to embed the defeasible attacks into our computational model, we have to deal with an important theoretical problem: what is the nature of the standpoint of the sub-discussions created to resolve the undercutting or rebutting attacks?

In Pragma-dialectics, a standpoint is a point of view about a proposition. But in the previous diagram, the standpoint in sub-discussions is the undercut or rebuttal itself. These attacks are arguments, so they are a set of premises supporting a conclusion (an argument involves an inference). This conclusion will be the premise (undercut) or the conclusion (rebuttal) of the attacked argument. However, obviously, an argument is not a point of view about a proposition.

In section 5 (classical formal logic), I considered, for simplicity sake, only one type of point of view about a proposition: claiming that the proposition is true. In this case, we can consider that the standpoint must be a proposition (to be more precise, 
the point of view of claiming that the proposition is true). But, which proposition? There are three options for the standpoint:

(a) The premises of the attacking argument

(b) The conclusion of the attacking argument

(c) The whole argument (the inference itself: premises, therefore conclusion)

Option (a) seems to be compatible with the concept of argument in Pragma-dialectics (an argument as a set of premises), but with such a standpoint, in the sub-discussion, contenders will not be able to attack or defend the conclusion or the inference itself. Therefore, we cannot accept it.

Option (b) seems to be more plausible. The conclusion of the attack is the proposition that contradicts the premise or the conclusion of the attacked argument. There is one problem, however: in the new sub-discussion, if it is ruled by Pragmadialectics' model of a critical discussion, the protagonist will be able to present any argument supporting the standpoint, not just the original argument (set of premises) presented in the main discussion. Thus, it seems that Pragma-dialectics' model of a critical discussion does not fit well in this case (we would have to modify some rules in order to allow only the original argument/attack to be presented).

Option (c) is the most natural solution when dealing with defeasible reasoning. However, turning an argument (in this case: premises, therefore conclusion) into a standpoint is not a trivial task. It will depend on the formalism we employ. In fact, turning an inference or a deduction into a point of view about a proposition is something that cannot be done in all models of reasoning (defeasible or not).

In conclusion, defeasible reasoning, as described here, does not fit well in Pragma-dialectics because of its account of standpoints in critical discussions.

Leaving aside this issue, we can try, anyway, to embed defeasible reasoning (undercuts and rebuttals) into our computational model of a critical discussion.

An undercutting attack seems to be very similar to the process of questioning the propositional content of an argument. After all, both attacks try to defeat the premises of the attacked argument. Moreover, the defense of the propositional content involves the possibility of starting a new sub-discussion, as we have to do with undercuts. However, there are important differences: 
1. The Intersubjective Identification Procedure is not necessary within undercutting attacks (the subdiscussion starts immediately after an undercut is raised), but it is mandatory in the model of a critical discussion

2. The sub-discussion will have a different standpoint and roles of protagonist/antagonist.

A rebutting attack, on the other hand, seems to be similar to the process of questioning the force of justification of the argument (diagram 4), because, in both cases (rebutting attack and questioning the force of justification), we are attacking the conclusion supported by the argument. However, Pragma-dialectics does not consider the possibility of starting a sub-discussion at this point and the Intersubjective Inference Procedure just tests the logical validity of the inference, without any other consideration.

In conclusion, if we want to embed defeasible reasoning into the model of a critical discussion, we have to change its rules (or, at least, modify existing ones).

The last issue I wish to consider is the possibility of "loops". An attack can be attacked by another attack, but this second attack can be attacked by a third attack... that can be attacked by the first one (loops can be much more complex). This is a complex issue in Computational Argumentation (cf. Pollock, 2009, pp. 177 ff.). If it is not treated properly, it can lead to infinite moves. Pragma-dialectics prohibits the repetition of the same dialectical move (Rule 13.a). We can try to apply it to loops, so that the same argument/attack cannot be presented twice. It can be a solution to avoid infinite loops, but it does not work well for defeasible reasoning. We can see one reason in the following example:

There are two contenders, A and B. There are two argument/attacks available, $r$ and $s ; \mathrm{r}$ and $\mathrm{s}$ attack each other (we have a simple loop); $r$ supports the standpoint of $\mathrm{A}$, and $s$ supports the standpoint of B.

First case:

1. A presents $r$

2. B attacks $r$ by presenting $s$

3. A cannot present $r$ again to attack $s$, so $r$ is defeated by $s$

4. B "wins" the critical discussion (her argument, supporting her standpoint, is successfully defended) 
Second case:

1. B presents $s$

2. A attacks $s$ by presenting $r$

3. B cannot present $s$ again, so $s$ is defeated by $r$

4. A "wins" the critical discussion

As we can see, the result depends on who presents her argument first. Actually, the contender who presents the argument first will "lose". That situation is not desirable at all, so we should think of other solutions to the "loop" issue. There are some solutions available in Computational Argumentation literature $^{38}$, but incorporating them into the model of a critical discussion would involve changes in the rules.

In conclusion, defeasible reasoning, as described here, does not fit well in the model of a critical discussion. It seems that some rules should be changed or added in order to deal with undercuts and rebuttals. This means that the model of a critical discussion is not independent from the model of reasoning chosen in the Opening Stage (see section 4 above) and, what is more, it cannot work with, at least, one possible reasoning model (defeasible reasoning, as described here).

\section{Conclusions}

I have presented a simple computational model of a critical discussion, as defined by Pragma-dialectics (for a single, nonmixed difference of opinion). This computational model is intended to allow a better understanding of Pragma-dialectics' ideal model - or at least, better than the well-known informal description of the 15 rules.

I have tried to use this computational model to analyze and evaluate different issues of Pragma-dialectics. On the one hand, the analysis reveals (section 3 ) that there is a limitation of the ideal model of a critical discussion: if we are dealing with a nonmixed difference of opinion, antagonist cannot present any argument against the standpoint defended by the protagonist, but rules force sub-discussions to be non-mixed. I have found a practical weakness: mixed differences of opinion are hard to

\footnotetext{
${ }^{38}$ Cf. (cf. Pollock, 2009, pp. 177 ff.). Abstract Argument Systems are another formalism, very popular in Computational Argumentation, which is focused on attacks between arguments, cf. (Baroni \& Giacomin, 2009) for an introduction and a discussion of ways to deal with loops. Intuitive solutions to the example above are: consider that both $r$ and $s$ are defeated; assign a "weight" to $r$ and $s$, in order to decide which is better...
} 
deal with, compared to non-mixed. But, because of the limitation explain above, most of argumentative discourse will have to be reconstructed as a mixed difference of opinion. A revision of the model is suggested in order to resolve both issues (the first, of course, is the important one).

On the other hand, I have pointed out that Pragmadialectics leaves undefined the "logical dimension" of argumentation (section 4), because it focuses on argumentative discourse, which is supposed to be independent from the model of reasoning/inference chosen. Nevertheless, I contended that it would be a good idea to go further in the computational model to test different models of reasoning/inference, which I did in sections 5 and 6 , for classical formal logic and defeasible reasoning. The result reveals that Pragma-dialectics is not so independent from the model of reasoning chosen as it should be. Specifically, it does not seem to work well with defeasible logic (a modification of the rules is needed to do it). Perhaps pragmadialecticians should pay more attention to the "logical dimension" of argumentation.

Finally, we can ask ourselves whether the model of a critical discussion can be used to produce argumentative discourse, or to guide actual argumentation (in natural language or as part of a computational multi-agent system). Van Eemeren and Grootendorst think that the model is "too technical for immediate use by ordinary discussants" (2004, p. 190), so they propose, in chapter 8 , a simple code of conduct for reasonable discussants (so called "ten commandments"). Our work shows that the model of a critical discussion, once it is modeled as we have done, is not so hard to understand and apply. However, we have found some problems to mend or, at least, to take into account if we want to use our model in order to guide or produce argumentative discourses (formal or informal). Pragma-dialecticians can argue that, since the model is not intended to be used in such a way, this is not a problem at all. However, if a model for analyzing and evaluating argumentative discourse cannot be used as a guide to produce good argumentation (no matters if "too technical" or hard to apply), we can take this fact as a symptom of possible basic problems. Consequently, it can be interesting to deepen the analysis.

In my view, all this would show that computational models of existing theories of argumentation can be a valuable tool for analyzing and appraising theoretical proposals within Argumentation Theory. 
Acknowledgements: I would like to thank Lilian BermejoLuque for her support and comments on previous drafts of this article and her help with its translation into English.

\section{References}

Antonelli, G. A. (2012). Non-monotonic logic (http://plato.stanford.edu/archives/win2012/entries/logicnonmonotonic/). In E. N. Zalta, The Stanford Encyclopedia of Philosophy (Winter 2012 Edition).

Baroni, P \& Giacomin, M (2009). Semantics of Abstract Argument Systems. In En I. Rahwan, \& G. R. Simari (Edits.), Argumentation in Artificial Inteligence. Dordrecht: Springer.

Bermejo Luque, L. (2011). Giving reasons. A pragmaticlinguistic approach to Argumentation Theory. Dordrecht: Springer.

Bermejo-Luque, L., Secades Gómez, A. "Commentary on: Jacky Visser's 'A Formal Account of Complex Argumentation in a Critical Discussion"', en Mohammed, D., \& Lewiński, M. (Eds.). Virtues of Argumentation. Proceedings of the 10th International Conference of the Ontario Society for the Study of Argumentation (OSSA), 22-26 May 2013. Windsor, ON: OSSA.

Besnard, P. \& Hunter, A. (2009). Argumentation Based on Classical Logic. In I. Rahwan, \& G. R. Simari (Edits.), Argumentation in Artificial Inteligence. Dordrecht: Springer.

van Eemeren, F. H. (2012). "Maniobras estratégicas: combinando lo razonable y lo efectivo en el discurso argumentativo", Acta Poética 33·1, 2012, pp. 19-47.

van Eemeren, F. H., \& Grootendorst, R. (1984). Speech Acts in Argumentative Discussions: A Theoretical Model for the analysis of discussions directed towards solving conflicts of opinion. Dordrecht: Foris Publications.

van Eemeren, F. H., \& Grootendorst, R. (2004). A Systematic Theory of Argumentation: The Pragma-dialectical Approach. Cambridge: Cambridge University Press.

García, A. J., Dix, J., \& Simari, G. R. (2009). Argument-based Logic Programming. In I. Rahwan, \& G. R. Simari (Edits.), Argumentation in Artificial Inteligence. Dordrecht: Springer.

Garrido, M. (2001). Lógica simbólica. Madrid: Tecnos.

Koons, R. (2013). Defeasible Reasoning. In E. N. Zalta, The Stanford Encyclopedia of Philosophy (Spring 2013 Edition). (http://plato.stanford.edu/archives/spr2013/entries/reasoningdefeasible/). 
Pollock, J. L. (2009). A Recursive Semantics for Defeasible Reasoning. In I. Rahwan, \& G. R. Simari (Edits.), Argumentation in Artificial Inteligence. Dordrecht: Springer.

Visser, J. "A formal account of complex argumentation in a critical discussion", Mohammed, D., \& Lewiński, M. (Eds.). Virtues of Argumentation. Proceedings of the 10th International Conference of the Ontario Society for the Study of Argumentation (OSSA), 22-26 May 2013. Windsor, ON: OSSA, pp. 1-14 